\title{
A CASE REPORT OF PERITONEAL INCLUSION CYST AFTER SUBTOTAL HYSTERECTOMY FOR RUPTURE UTERUS
}

Leila Gracelyn ${ }^{1}$, Jothinathan ${ }^{2}$

\section{HOW TO CITE THIS ARTICLE:}

Leila Gracelyn, Jothinathan. "A Case Report of Peritoneal Inclusion Cyst after Subtotal Hysterectomy for Rupture Uterus". Journal of Evolution of Medical and Dental Sciences 2014; Vol. 3, Issue 58, November 03;

Page: 13188-13191, DOI: 10.14260/jemds/2014/3753

\begin{abstract}
We are reporting a case of 26 year old female who presented with progressive severe lower abdominal pain and abdominal distension for 2 months. MRI confirmed a peritoneal inclusion cyst. She had a history of laparotomy done for rupture uterus which eventually led to the formation of dense pelvic adhesions and a large peritoneal inclusion cyst. Laparotomy was done, adhesions were released and cyst excision done. The case is presented here to emphasize the need to consider a diagnosis of peritoneal inclusion cyst in any person with a prior history of abdominal surgery.

KEYWORDS: BENIGN CYSTIC MESOTHELIOMA OF PERITONEUM, PERITONEAL INCLUSION CYST, PERITONEAL MESOTHELIAL CYST, PERITONEAL PSEUDOCYST.
\end{abstract}

INTRODUCTION: A peritoneal inclusion cyst is a type of cyst like structure that appears in relation to the peritoneum and results from a non-neoplastic reactive mesothelial proliferation. ${ }^{[1]}$ It is also known as Benign Cystic Mesothelioma of Peritoneum/Peritoneal Pseudocyst/Peritoneal Mesothelial Cyst. They are usually caused by accumulation of ovarian fluid that is contained by peritoneal adhesions. The trapped ovary produces physiologic fluid responsible for fluid within these cysts.[2] During the reproductive years, fluid produced by the ovaries is normally absorbed by the peritoneum. ${ }^{[3]}$

When the integrity of the peritoneum is disrupted as a result of previous surgery, trauma, inflammation due to PID or endometriosis, the peritoneum has decreased ability to absorb the fluid. [4] In addition surgical adhesions can trap the ovarian fluid that is no longer being absorbed by the disrupted peritoneum producing a complex cystic mass. Functionally active ovaries and adhesions are thus essential for development of peritoneal inclusion cyst compatible with the presentation of this lesion after the onset of puberty. Pseudocysts, lack true cyst walls. Individual locules may contain serous fluid, gelatinous fluid or hemorrhagic fluid.

CASE REPORT: A 25 year old P2L1 married since 4 years presented with severe abdominal pain and distension of abdomen for the past 2 months. She had a prior history of laparotomy done for rupture uterus. During the laparotomy it was found that there was a hemoperitoneum of about 3 liters of blood. Since the uterine rent was beyond repair, subtotal hysterectomy was done. Ultrasound showed a peritoneal inclusion cyst.

Further diagnosis was confirmed by MRI which showed a large lobulated predominantly cystic mass $(12 \mathrm{X} 10.5 \mathrm{X} 9 \mathrm{~cm})$ with internal septations in the pelvis suggestive of peritoneal inclusion cyst. The cyst had no solid fat component, hemorrhage or calcification. Laparotomy revealed dense adhesions and a large inclusion cyst of size 12 X $10.5 \mathrm{~cm}$ occupying the pelvis. Left tube and the ovary were normal and were found trapped within the inclusion cyst. 
Excision of the cyst and release of adhesions done. Right tube and ovary were normal. On microscopic examination, cyst walls were lined by a thin layers of flattened mesothelial cells with no evidence of neoplasm.

DISCUSSION: The clinical presentation in the case reported here can mimic an infected paraovarian cyst, hydrosalphinx, pyosalphinx, endometrioma, cystic ovarian neoplasm, macrocystic lymphatic malformations, pseudomyxoma peritonii or omental cysts. [5] The time between the most recent surgery and detection of the PIC has been reported to the range from 6 months to 20years. The most common presenting symptom in patients with a peritoneal inclusion cyst is acute or chronic lower abdominal pain or pelvic pain.

There may or may not be palpable abdominal or pelvic masses. Some patients present with infertility, urinary frequency, urinary incontinence, dyspareunia and constipation. The imaging features of these cysts are important for diagnosis. Ultrasound is the most frequently used modality in the initial workup of any patient with pelvic pain. When adhesions surround the ovary and fluid accumulates forming a cystic mass, the trapped ovary has an appearance of "spider in a web". [6] The ovary or the spider is located centrally or laterally within network of web like septations.

On CT, peritoneal inclusion cyst depict a cystic mass with regular or irregular borders with attenuation properties of fluid or hemorrhage.[7] MR images demonstrate cystic lesions with low T1 signals and higher T2 signals consistent with serous fluid. MRI may also be helpful in demonstrating the extraovarian nature of the fluid collection. Macroscopically, they are thin walled unilocular or multilocular cysts arising from pelvic organs, side wall or cul de sac.

They are rarely free floating in the abdominal cavity and may be adherent to surrounding structures. The presence of thick walls, nodularity, papillary excrescences or other solid components excludes the diagnosis of PIC Tissue sample is necessary for definitive diagnosis. ${ }^{[8]}$ Microscopically mesothelial cells are arranged in single layers. These cells may demonstrate squamous metaplasia and formation of connective tissues, both are adaptive changes to inflammation. No nuclear or cellular atypia are identified.

Both conservative and surgical treatments are used. Oral contraceptives are used to suppress ovulation and pain. It is also thought to decrease the amount of fluid produced by the ovary. Intermittent pain medication and GnRh analogues [9] can also be used. Image guided percutaneous or transvaginal fluid aspiration can be done. [10]

Sclerotherapy can also be done. [11] Surgical open resection of adhesions, cyst excision or laparoscopic adhesiotomy may be performed in patients with acute or chronic abdominal or pelvic pain, infertility, dyspareunia, tenesmus and urinary frequency. Surgical excision has risk of recurrence of $30-50 \%$. ${ }^{[11]}$ In our case because of continued pain and distension, definitive treatment was done.

CONCLUSION: The case is presented here to emphasize the importance of entertaining a diagnosis of peritoneal inclusion cyst in any patient with a prior history of surgery with simple or complex cystic masses demonstrated on imaging. Though these patients have minimal mortality, the rates of morbidity are very high. The goal for such a chronic disease should not be cure, but symptomatic relief through individualization of treatment. 


\section{REFERENCES:}

1. Ross MJ, Welch WR, Scully RE. Multilocular peritoneal inclusion cysts [so called cystic mesothelioma]. Cancer 64: 1336-1346 Cross Ref.

2. Hoffer FA, Kozakewich H, Colodny A, Goldstein DP. Peritoneal inclusion cysts: ovarian fluid in peritoneal adhesions. Radiology: 169: 189-191.

3. Koninckx PR, Renaer M, Brosens IA. Origin of peritoneal fluid in women: an ovarian exudation product. Br J Obstet Gynaecol. 1980; 87: 177-83.

4. Verger C, Luger A, Moore HL et al. Acute changes in peritoneal morphology and transport properties with infectious peritonitis and mechanical injury. Kidney Int. 1983; 23: 823-31.

5. Jain KA. Imaging of peritoneal inclusion cysts. AJR Am J Roentgenol. 2000; 174(6): 1559-63. AJR Am J Roentgenol (full text) - Pubmed citation

6. Kim JS, Lee HJ, Woo SK et al. Peritoneal inclusion cysts and their relationship to the ovaries: evaluation with sonography. Radiology. 1997; 204 (2): 481-4. Radiology (abstract) - Pubmed citation.

7. Jeong YJ, Kim S, Kwak SW et al. Neoplastic and nonneoplastic conditions of serosal membrane origin: CT findings. Radiographics. 28 (3): 801-17. doi:10.1148/rg.283075082 - Pubmed citation

8. Soreide JA, Soreide K, Korner $\mathrm{H}$ et al. Benign peritoneal cystic mesothelioma. World J Surg. 2006; 30: 560-6.

9. Letterie GS, Yon JL. Use of a long-acting GnRH agonist for benign cystic mesothelioma. Obstet Gynecol. 1995; 85: 901-3.

10. Inman DS, Lambert AW, Wilkins DC. Multicystic peritoneal inclusion cysts: the use of CT guided drainage for symptom control. Ann R Coll Surg Engl. 2000; 82: 196-7.

11. Jeong JY, Kim SH. Sclerotherapy of peritoneal inclusion cysts: preliminary results in seven patients. Korean J Radiol. 2 (3): 164-70. Korean J Radiol (link) - Free text at pubmed - Pubmed citation.

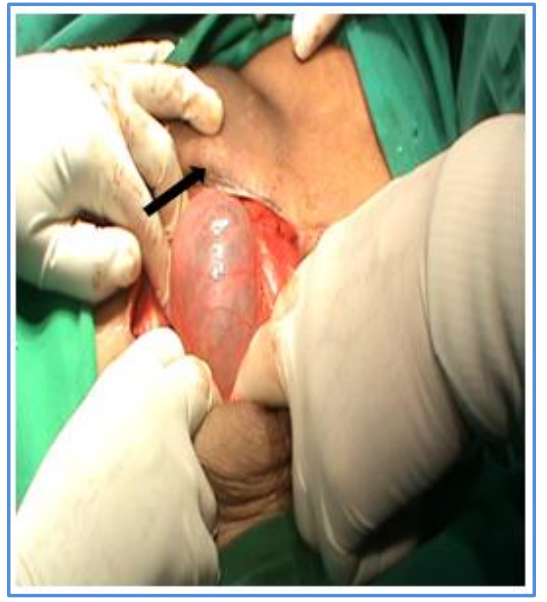

Fig. 1: Black arrow shows peritoneal inclusion cyst on opening the abdomen

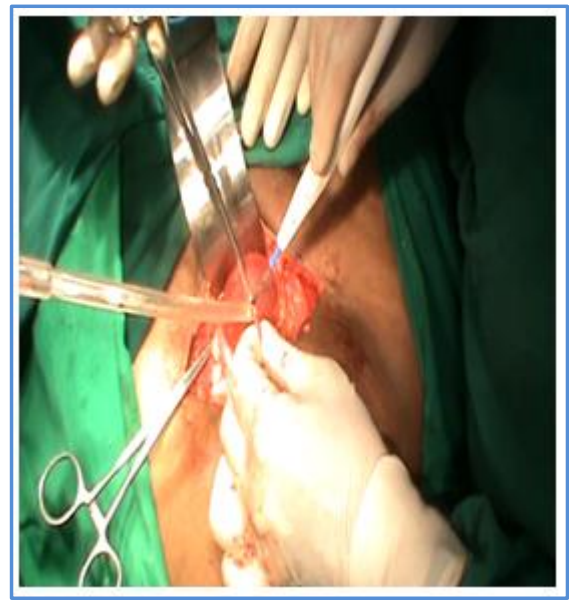

Fig. 2: Shows the cyst being opened 


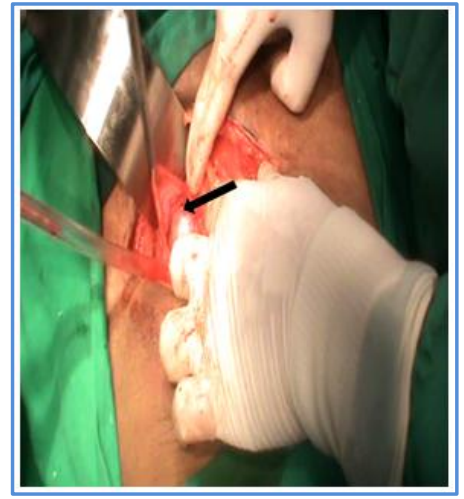

Fig. 3: Shows the left ovary trapped within the cyst wall

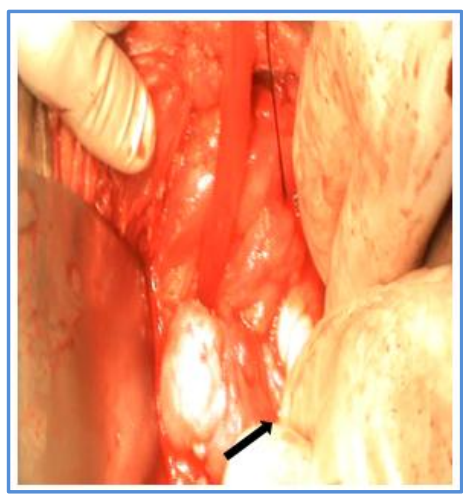

Fig. 4: Shows cervical stump left behind after subtotal hysterectomy for rupture uterus

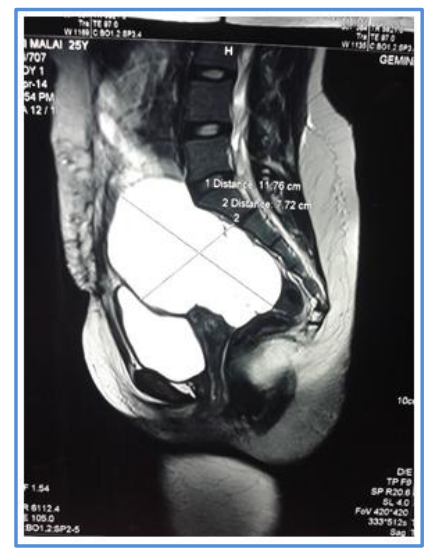

\section{Fig. 5: Shows the MRI image of the cyst}

\section{AUTHORS:}

1. Leila Gracelyn

2. Jothinathan

\section{PARTICULARS OF CONTRIBUTORS:}

1. Associate Professor, Department of Obstetrics and Gynecology, ACS Medical College.

2. Consultant General and Laparoscopic Surgeon, Department of General Surgery, Vee Care Hospital.

\author{
NAME ADDRESS EMAIL ID OF THE \\ CORRESPONDING AUTHOR: \\ Dr. Leila Gracelyn, \\ Associate Professor, \\ ACS Medical College, \\ C-8/100, Kendriya Vihar, \\ Velappanchavadi, \\ Chennai-77. \\ Email: jm1078@rediffmail.com
}

Date of Submission: 10/10/2014. Date of Peer Review: 11/10/2014. Date of Acceptance: 30/10/2014. Date of Publishing: 03/11/2014. 